\title{
PAULINA CHIZIANE E A HISTÓRIA DA POLIGAMIA
}

OLIVEIRA, Jurema

Paulina Chiziane é autora de A balada de amor ao vento (1990), Ventos do apocalipse (1995), O sétimo juramento (1999) e Niketche: uma história da poligamia (2002). Estas duas últimas obras criticam os costumes e a postura patriarcal da sociedade moçambicana, e também a prática de se obter o poder a qualquer preço. Estas obras distintas têm em comum a denúncia dos tortuosos meios encontrados por um sistema social que silencia as vozes femininas em prol de uma valoração das ações e feitos masculinos.

Em O sétimo juramento, os valores animistas constituem o foco da narrativa, que traz à tona uma prática recusada pelo sistema colonial, mas subentendida no comportamento sócio-cultural vigente durante o processo revolucionário moçambicano. No dizer de Leite:

O mundo do feitiço e dos mitos esteve sempre ligado ao comportamento sócio-cultural da maior parte dos intervenientes activos na nova política social de Moçambique, embora de forma mais ou menos latente. O sétimo juramento, através de uma história de família, de que Vera, é uma das protagonistas, coloca-nos perante o dilema da confrontação com esse mundo mágico-espiritual, que questiona, entre outras coisas, a assimilação dos costumes, a cristalização, resultados ainda do tempo colonial. Questiona ainda os primeiros anos do pós-independência em que foram proibidas as práticas feiticistas e religiosas. Este "apagamento" das tradições religiosas animistas, e a ocidentalização dos costumes, levou, por um lado, ao seu recrudescimento clandestino, por outro à incapacidade de defesa, e compreensão comportamental, por desconhecimento dessas mesmas práticas e tradições antigas (2003, p. 69).

O choque cultural presente em $O$ sétimo juramento pode ser percebido nesta passagem: 
- Diz-me avó, pode o meu filho estar possesso, pode?

- Os espíritos fazem a vítima sofrer. Abrem caminhos, fecham caminhos, transtornam. Dão cabo da cabeça, enlouquecem. (...) Estou a rever memórias do tempo antigo. (...) As almas não morrem, Vera, encarnam-se. E este filho nunca foi teu nunca te pertenceu. Começa por decifrar o mistério do seu nome (...). No nome está a raiz do problema. Os antepassados sempre disseram A VITO I MPONDO! (CHIZIANE, 1999, p.59).

Além da fragmentação conceitual acerca dos rituais do passado - visíveis na fala da personagem que protagoniza a cena de possessão do filho - constata-se no decorrer da leitura que ela se torna vítima da ambição de um homem que faz uma "viagem iniciática ao mundo dos mortos, não olhando os meios, sacrificando ritualmente a família para conseguir os seus almejados objetivos" (LEITE, 2003, p.70).

Neste cenário de poder masculino, a figura feminina encontrase duas vezes violentada pelos códigos sociais estabelecidos: pelo patriarcado e pela ausência de conhecimento sobre as tradições religiosas da comunidade a que pertence, e que a ajudariam a compreender pelo menos os efeitos das ações daquele homem nos membros da família, quando estabelece um pacto com os "mundos infernais" para obter rapidamente o poder desejado.

A crítica aos costumes patriarcais destoantes em o sétimo juramento também será feita pela via da ironia em Niketche: uma história da poligamia. Segundo Leite, esta obra se inscreve numa linha narrativa feminina de crítica à poligamia, que se tornou recorrente no cenário literário de mulheres africanas que buscam denunciar por meio da paródia a "forma perversa como a poligamia foi adulterada na sociedade urbana, não se respeitando os direitos que as mulheres tinham na sociedade tradicional" (LEITE, 2003, p.70). 
Niketche: uma história da poligamia conta a história de Tony, funcionário da polícia e sua mulher Rami, casados há vinte anos. Em um determinado momento, Rami descobre que seu marido é polígamo: tem outras quatro mulheres e vários filhos com cada uma. As esposas do Tony estão espalhadas pelo país: em Maputo, em Inhambane, na Zambézia, em Nampula e em Cabo Delgado.

O tratamento dado aos temas sobre a mulher por escritoras africanas na pós-revolução constitui um ponto de vista diferenciado e crítico que contribui para a construção de projetos descoloniais. Num cenário complexo, Paulina Chiziane explicita fundamentos de um saber africano pautado num:

conhecimento esotérico e oculto, da tradição religiosa e cultural: práticas de magia, feitiçaria, rituais de morte e de viuvez, rituais de iniciação sexual, relato das normas e tabus existentes nas relações familiares e entre homem e mulher (LEITE, 2003, p.73).

$\mathrm{Na}$ qualidade de primeira esposa, Rami sente-se desprezada, apesar de avaliar o tempo de casamento como uma conquista:

Vinte anos de casamento é um recorde nos tempos que correm. Modéstia à parte, sou a mulher mais perfeita do mundo. Fiz dele o homem que é. DeiIhe amor, dei-lhe filhos com que ele se afirmou nesta vida. Sacrifiquei os meus sonhos pelos sonhos dele. Dei-lhe a minha juventude, a minha vida. Por isso afirmo e reafirmo, mulher como eu, na sua vida, não há nenhuma! Mesmo assim, sou a mulher mais infeliz do mundo. Desde que ele subiu de posto para comandante da polícia e o dinheiro começou a encher as algibeiras, a infelicidade entrou nesta casa (CHIZIANE, 2004, p.14).

O descontentamento leva Rami a buscar explicações para a falta de afeto e descobre que sua vida:

É um rio morto. No meu rio as águas pararam no tempo e aguardam que o destino traga a força do 
vento. No meu rio, os antepassados não dançam batuques nas noites de lua. Sou um rio sem alma, não sei se a perdi e nem sei se alguma vez tive uma. Sou um ser perdido, encerrado na solidão mortal (CHIZIANE, 2004, p.18).

As águas do rio de Rami precisam ser despertadas. Nesse sentido, ela pede a Deus a força que no passado - anterior a colonização - os moçambicanos encontravam nos rituais animistas típicos da tradição:

Meu Deus ajuda-me a descobrir a alma e a força do meu rio. Para fazer as águas correr, os moinhos girar, a natureza vibrar. Para trazer ao meu leito a luz de todas as estrelas do firmamento e deixar o arco-íris mergulhar-me em toda a sua imensidão (CHIZIANE, 2004, p.18).

Rami, a primeira esposa de Tony vive ao sul de Moçambique, região que de acordo com uma das amantes teria sofrido maior influência das práticas eurocêntricas:

- Não tens culpa - comenta a Saly. - Vocês do sul deixaram-se colonizar por essa gente da Europa e os seus padres que combatiam as nossas práticas. Mas que valor tem esse beijo comparado com o que temos dentro de nós? Depois trouxeram a pornografia, essa estupidez só para enganar os incompetentes e entreter os tolos (CHIZIANE, 2004, p.181).

Diante do impasse da experiência de ser uma mulher marcada por ausências e falta de experiências afetivas mais completas, Rami interroga a mãe acerca de sua aparência e das lições de amor que não recebeu:

O que acha do meu peso, mãe? Devo emagrecer como essa Julieta? Isso também é fácil, posso corrigir o corpo com massagens e ginástica aeróbica. Mas tenho medo de emagrecer. Os homens pretos gostam de mulheres rechonchudas, com almofadas para frente, almofadas para trás, 
assim como eu. É verdade, mãe, essas mulheres todas prendem o Tony com encantos mágicos que não tenho. Por que não me fizeste mais bonita do que elas, mãe? Por que não me deste lições de amor para viver sem dor, minha mãe? (CHIZIANE, 2004, p.99).

A personagem Rami representa uma parcela da mulher moçambicana sem os encantos das macuas que preparam a alma para dançar o niketche. Um ritmo tradicional do norte de Moçambique:

Niketche. A dança do sol e da lua, dança do vento e da chuva, dança da criação. Uma dança que mexe, que aquece. Que imobiliza o corpo e faz a alma voar. As raparigas aparecem de tangas e missangas. Movem o corpo com arte saudando o despertar de todas as primaveras. Ao primeiro toque do tambor, cada um sorri, celebrando o mistério da vida ao sabor do niketche. Os velhos recordam o amor que passou, a paixão que se viveu $e$ se perdeu. As mulheres desamadas reencontram no espaço o príncipe encantado com quem cavalgam de mãos dadas no dorso da lua. Nos jovens desperta a urgência de amar, porque o niketche é sensualidade perfeita, rainha de toda sensualidade. Quando a dança termina, podem ouvir-se entre os assistentes suspiros de quem desperta de um sonho bom (CHIZIANE, 2004, p.160-161).

A narrativa se desenvolve num cenário repleto de contrastes e nos leva a descobrir juntamente com Rami o desconhecido território do norte de Moçambique:

- A nossa sociedade do norte é mais humana explica a Mauá. - A mulher tem direito à felicidade e à vida. Vivemos com um homem enquanto nos faz feliz. Se estamos aqui, é porque a harmonia ainda existe. Se um dia o amor acabar, partimos à busca de outros mundos, com a mesma liberdade dos homens. (...) No sul a sociedade é habitada por mulheres nostálgicas. Dementes. Fantasmas. No sul as mulheres são exiladas no seu próprio 
mundo, condenadas a morrer sem saber o que é amor e vida. No sul as mulheres são tristes, são mais escravas. Caminham de cabeça baixa. Inseguras. Não conhecem a alegria de viver. Não cuidam do corpo, nem fazem massagens ou uma pintura para alegrar o rosto. Somos mais alegres, lá no norte. Vestimos de cor, de fantasia. Pintamonos, cuidamo-nos, enfeitamo-nos. Pisamos o chão com segurança. Os homens nos oferecem prendas, ai deles se não nos dão uma prenda. Na hora do casamento vem construir o lar na nossa casa materna e quando o amor acaba, é ele quem parte. No norte as mulheres são mais belas (CHIZIANE, 2004, p. 175).

Niketche: uma história da poligamia coloca o leitor diante de uma narrativa que cenariza mundos distintos por meio de um discurso que pontua ora um universo sulista, ora um espaço nortenho. De um lado, detectamos as experiências de personagens cuja memória do corpo está inserida nas práticas pregadas pela razão imperial/colonial como bem define Mignolo em seu texto "Desobediência epistêmica: a opção descolonial e o significado de identidade em política".

Rami representa gerações de mulheres que aprenderam com suas mães como deveriam se comportar para garantir um casamento, o lugar de esposa. Sendo assim, conectadas aos princípios eurocêntricos, as mulheres do sul compõem um quadro social que remonta um patriarcalismo oriundo da "colonialidade e da reprodução da matriz colonial do poder" (MIGNOLO, 2008, p.313) que visa inculcar no sujeito colonizado os valores universais abstratos como os preceitos judaico-cristãos: "no passado os homens deixaram-se vencer pelos invasores que impuseram culturas, religiões e sistemas a seu bel-prazer" (CHIZIANE, 2004, p.93).

O descompasso constitui-se na mola mestra que impulsiona a narrativa de Niketche: uma história da poligamia. Se de um lado, o discurso colonialista está presente nas práticas das mulheres sulistas, 
por outro lado o discurso descolonial se faz presente nas vozes de mulheres nortenhas que não querem ser propriedade e abominam a ideia de que "Quem investe cobra, porque é preciso que o investimento renda" (CHIZIANE, 2004, p.212).

Paulina Chiziane constrói uma narrativa marcada por várias vozes que sinaliza um desvelar a tradição, a colonialidade e a descolonialidade: De acordo com Macamo (2002), o conhecimento social em África pode ser dividido em três momentos nomeadamente o saber tradicional, o saber colonial e o saber africano. Cabe ressaltar que o sentido de "saber" proposto aqui está vinculado ao conceito de discurso disseminado pela ciência da literatura.

Nesse sentido, o saber tradicional vincula-se basicamente às práticas ritualísticas, como aquelas desenvolvidas pelas mulheres nortenhas que dançam niketche e frequentam uma escola de amor:

Trata-se de um saber que muitas vezes não é verbalizado e encontra expressão em situações rituais onde se produz e confirma a ordem social. Os mitos fundadores de linhagens ou legitimidades de poder constituem momentos privilegiados deste tipo de saber (MACAMO, 2002, p. 11).

Em Niketche: uma história da poligamia, as normas e os preceitos da poligamia tradicional são relatas no capítulo dezessete:

O ciclo do lobolos começou com a Ju. Foi com dinheiro e não com gado. Lobolou-se a mãe, com muito dinheiro, num lobolo-casamento. As crianças foram legalmente reconhecidas, mas não tinham sido apresentadas aos espíritos da família. Era preciso trazê-las do tecto da mãe para a sombra do patriarcal num acto de lobolo-perfilha, uma forma de legitimá-las uma vez que nasceram fora das regras de jogo de uma família polígama. Depois fez-se o lobolo da Lu e dos filhos. As nortenhas espantaram-se. Essa história de lobolo era nova para elas. Queriam dizer não por ser contra os seus costumes culturais. Mas envolve dinheiro e muito dinheiro. Dinheiro para os pais, dinheiro para elas, e para os filhos. 
- O meu Tony, ao lobolar cinco mulheres, subiu ao cimo do monte - diz a minha sogra. - Ele é a estrela que brilha no alto e como tal deve ser tratado. E tu, Rami, és a primeira (CHIZIANE, 2004, p. $124-125$ e 126).

A narradora ao situar o leitor em relação a uma prática sulista tradicional, alimenta um presente repleto de valores típicos, mas adulterados pelas ações de um projeto implementado pela razão imperial/colonial. E para ampliar nossas reflexões, recupera-se aqui um trecho do ritual kutchinga que ocorre oito dias depois da viuvez:

Agora falam do kutchinga, purificação sexual. Os olhos dos meus cunhados, candidatos ao sagrado acto, brilham como cristais. Cheira a erotismo no ar. A expectativa cresce. Sobre quem cairá a bendita sorte? Quem irá herdar todas as esposas do Tony? Fico assustada. Revoltada. Minha pele se encharca de suor e medo. Meu coração bate de surpresa infinda. Kutchinga! Eu serei tchingada por qualquer um. E todos aguçam os dentes para me tchingar a mim. A parede é firme e fria. Amparame. O dorso do chão é duro, é seguro. Suporta-me É tão cruel e tão malvada esta gente... Peço a qualquer Deus qualquer socorro. Ninguém me ajuda, nem Deus, nem santos. Kutchinga é lavar o nojo com beijos de mel. É inaugurar a viúva na nova vida, oito dias depois da fatalidade. Kutchinga é carimbo, marca de propriedade. (CHIZIANE, 2004, p. 212).

$\mathrm{Na}$ construção do quadro de práticas tradicionais explicitadas em Niketche, destaca-se aqui a história da moela na culinária moçambicana e de quem deve comer esse ingrediente sagrado:

- Aí é que está o grande mal - diz um velho. Falas de moelas. Eu estou a falar de uma moela. É preciso começar a compreender a diferença entre moelas e moela.

- Diferença?

- Moelas de aviário são uma coisa. Moela, daquela galinha amorosamente depenada e carinhosamente assada para o marido, é outra 
coisa. É dessa moela que estamos a falar. Não foram educadas pelas vossas mães? A senhora - 0 velho dirige-se à minha mãe - não educou a sua filha. Como primeira esposa é a principal responsável por essa anarquia. Tem que voltar a ensinar que a moela é sagrada. A moela e não as moelas.

A minha mãe chora em silêncio. O seu choro é um canto de ausência, de dor e saudade. Pela irmã que morreu na savana distante nas garras de um leopardo, por causa de uma moela de galinha. Pela humilhação que sofremos eu e ela, duas gerações distintas seguindo o mesmo trilho. Revolto-me. Estou disposta a abrir a boca, a soltar todos os sapos e lagartos, a incendiar tudo e vingar a honra da minha mãe ultrajada sem sequer olharem para a sua idade. De repente li a mensagem de paz nos olhos da minha mãe. Ela não quer que eu deixe falar a voz do silêncio.

- Esses matadouros são um atentado aos nossos costumes - vocifera uma outra velha -, a civilização está contra a nossa cultura (CHIZIANE, 2004, p. 153 e 154).

Na visão de Amadou Hampâté Bâ,

a tradição confere a Kuma, a palavra, não apenas poder criador, mas também a dupla função de conservar e destruir. Por isso, a palavra é por excelência 0 grande agente ativo da magia africana. Mas para que a palavra produza todo o seu efeito, é preciso que seja acompanhada ritmicamente, porque o movimento tem necessidade de ritmo, pois ele próprio se baseia no segredo dos números. É necessário que a palavra reproduza o vaivém que constitui a essência do ritmo (1993, p. 17).

O ritmo estabelecido pelos rituais tradicionais em certa medida foram rompidos no estágio de fixação do saber colonial em África. Ainda de acordo com Macamo (2002), este saber costuma ser conotado com a disciplina da antropologia. Nos anos setenta, com a crescente influência da perspectiva marxista nas ciências sociais, estabeleceu-se o hábito de criticar a antropologia pela sua 
proximidade com o sistema colonial (p. 11). Essa critica fundamentase na prática, ou melhor, no método usado por alguns antropólogos que direta ou indiretamente serviram aos propósitos dos regimes coloniais, mas isso não é motivo para se atrelar a disciplina às práticas coloniais.

O saber colonial consiste na invenção de valores para uma intervenção direta nas práticas sociais, em especial na formação familiar exposta por Paulina Chiziane em Niketche: uma história da poligamia:

Poligamia é o destino de tantas mulheres neste mundo desde os tempos sem memória. Conheço um povo sem poligamia: o povo macua. Este povo deixou as suas raízes e apogalimou-se por influência da religião. Islamizou-se. Os homens deste povo aproveitaram a ocasião e converteramse de imediato. Porque poligamia é poder, porque é bom ser patriarca e dominar. Conheço um povo com tradição poligâmica: o meu, do sul do meu país. Inspirado no papa, nos padres e nos santos, disse não à poligamia. Cristalizou-se. Jurou deixar os costumes bárbaros de casar com muitas mulheres para tornar-se monógamo ou celibatário. Tinha o poder e renunciou. A prática mostrou que com uma poligamia tipo ilegal, informal sem cumprir os devidos mandamentos. Um dia dizem não aos costumes, sim ao cristianismo e à lei. No momento seguinte, dizem não onde disseram sim, ou sim onde disseram não (CHIZIANE, 2004, p.92).

O saber colonial produziu uma sociedade:

africana fictícia, mas real, como artefacto do poder colonial. Portanto, o interesse português pelos usos e costumes tradicionais em Moçambique, consubstanciado em profusos estudos realizados principalmente por administradores coloniais foi, portanto, principalmente motivado pela necessidade de inventar uma sociedade africana susceptível de intervenção colonial (MACAMO, 2002, p. 14). 
Em relação ao saber africano, podemos dizer que é uma projeção para o futuro:

Este saber africano não se deve confundir com o saber tradicional. O que se tem em mente é um tipo de saber que consiste na projecção duma ideia de África no futuro a partir da confrontação entre o indivíduo e as condições objectivas da sua existência no momento actual (MACAMO, 2002, p.15).

A projeção de um saber africano nasce com as ideias disseminadas por Senghor, Aimé Cesaire, Du bois, dentre outros pensadores de movimentos como o pan-africanismo e a negritude, que ao definir a África como uma comunidade de saberes e valores distintos daqueles pregados pelo ocidente idealizaram um futuro resultante das experiências cotidianas.

No livro Para quando a África? (2006), Ki-Zerbo faz a seguinte reflexão:

A história anda sobre dois pés: o da liberdade e o da necessidade. Se considerarmos a história na sua duração e na sua totalidade, compreenderemos que há, simultaneamente, continuidade e ruptura. Há períodos em que as invenções se atropelam: são as fases da liberdade criativa. $E$ há momentos em que, porque as contradições não foram resolvidas, as rupturas se impõem: são as fases da necessidade. Na minha compreensão da história, os dois aspectos estão ligados. A liberdade representa a capacidade do ser humano para inventar, para se projetar para diante rumo a novas opções, adições, descobertas. $\mathrm{E}$ a necessidade representa as estruturas sociais, econômicas e culturais que, pouco a pouco, vão se instalando, por vezes de forma subterrânea, até se imporem, desembocando à luz do dia numa configuração nova. De uma certa maneira, a parte da necessidade da história escapa-nos, mas podese dizer que, mais cedo ou mais tarde, ela há de se impor por si própria (2006, p. 17). 
A ideia de a história caminhar sobre dois pés fortalece significativamente os preceitos dos sistemas comunitários de ruptura com um conhecimento construído a partir do "conhecimento ocidental e razão imperial/colonial" que neutralizou as experiências de povos fora do eixo eurocêntrico. O despertar desses grupos toma força à medida que novas estratégias de ruptura são valorizadas. Sendo assim, quando Ki-Zerbo (2006) diz que "não podemos separar os dois pés da história - a historia-necessidade e a historia-invenção" ( $\mathrm{p}$. 17), porque no momento preciso a primeira se impõe para que o sujeito invente novos caminhos para romper com um projeto saturado e excludente como o imperial/colonial, aonde "as identidades construídas pelos discursos europeus modernos eram raciais (isto é, a matriz racial colonial) e patriarcais" (MIGNOLO, 2008 , 290). Num segundo estágio do processo em que a históriainvenção fixou-se, a projeção do futuro encontra respaldo naquilo silenciado pelo discurso eurocêntrico, as práticas comunitaristas que podem e devem ser fortalecidas pela "identidade em política" (MIGNOLO, 2008, p. 290).

\section{REFERÊNCIAS :}

ABDALA JUNIOR, Benjamin. De vôos e ilhas: literatura e comunitarismos. São Paulo: Ateliê Editorial, 2003.

CHIZIANE, Paulina. Niketche: uma história da poligamia. São Paulo: Companhia das Letras, 2004.

HAMPÂTÉ - BÁ, Amadou. "Palavra africana". In: o correio da Unesco. Ano 21, número 11, Paris; Rio de Janeiro, novembro de 1993.

KI - ZERBO, Joseph. Para quando a África? Rio de Janeiro, 2006.

LEITE, Ana Mafalda. Literaturas africanas e formações póscoloniais. Maputo: Imprensa Universitária, 2003.

MACAMO, Elísio. A constituição de uma sociologia das sociedades africanas. Estudos Moçambicanos, 19: s.l: s.n, 2002, 
pp. 5-26. In: http://www.casadasafricas.org.br/site/img/upload/468250.pdf. Acesso em 23/05/2011.

MIGNOLO, Walter D. "Desobediência epistêmica: a opção descolonial e o significado de identidade em política". Cadernos de Letras. Niterói - RJ, número 34, p. 287-325, 2008. 